
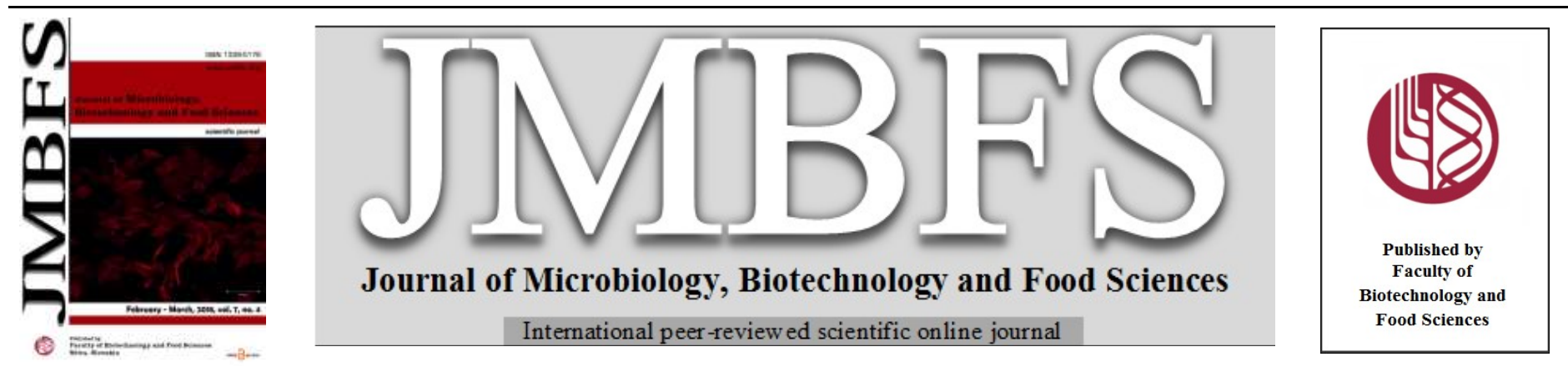

\title{
BIOSYNTHETIC PRODUCTION OF CAROTENOIDS USING YEAST STRAINS OF GENUS RHODOTORULA ON THE CHEAP BEER WORT SUBSTRATE
}

\author{
Natalya Vasilievna Besarab ${ }^{* 1}$, Konstantin Mikhailovich Gerasimovich ${ }^{1}$, Anna Valerievna Kanterova ${ }^{I}$, Galina Ivanovna Novik ${ }^{l}$
}

Address(es): Natalya Besarab,

${ }^{1}$ Institute of Microbiology, Belarus National Academy of Sciences, Minsk, Belarus, Kuprevich str. 2, 220141, Minsk, Belarus. Phone/Fax: +375 (17) 267-47-66.

*Corresponding author: natal-vasilna@rambler.ru

doi: $10.15414 / j m b f s .2018 .7 .383-386$

ARTICLE INFO

Received 10. 7. 2017

Revised 27. 10. 2017

Accepted 20.11.2017

Published 1. 2. 2018

Regular article

open $\partial_{\text {ACCESS }}$

\begin{abstract}
Carotenoids having primary significance for animal husbandry, medicine and food industry are objects of studies to optimize their production conditions and to establish their complex role in living systems. Synthesis of carotenoids by microorganisms is preferential for industrial use due to their natural origin and possibility of combining production with waste disposal. Native microbial strains are the basis for selecting superproducers of organic pigments. In this study, the red yeasts of Rhodotorula genus were incubated in beer wort medium at initial cultural parameters (sugar concentration 6 degrees Balling, temperature $26^{\circ} \mathrm{C}$, stirring rate $200 \mathrm{rpm}, 4$ days of fermentation). Analysis of biomass and carotenoid production by Rhodotorula yeast was performed under defined conditions. Two strains of $R$. glutinis BIM Y-253 and BIM Y-158 synthesizing over $100 \mu \mathrm{g}$ carotenoids per $1 \mathrm{~g}$ biomass, the mark corresponding to the average level of production, were selected. The concentration of carotenoids generated by strain $R$. glutinis BIM Y-253 in the nutrient medium exceeded $1 \mathrm{mg} / 1$. Screening of red yeast for the types of synthesized carotenoids showed predominance of torulene- and torularhodin-like compounds in isolated total pigment fractions. At the following experimental stage the effect of organic supplements on production of biomass and carotenoids by the selected strain R. glutinis BIM Y-253 was studied. Yeast incubation with $0.05 \%$ malic acid - the substrate for final reaction of TCA cycle, and fine grinding of biomass resulted in average carotenoid yield 3,5 mg/l. Our findings demonstrate the potential carotenoid productivity of red yeast at the initial values of incubation parameters, and illustrate the impact of organic compounds on biosynthetic efficiency of native yeast culture.
\end{abstract}

Keywords: Red yeast, Rhodotorula, carotenoids, natural substrate, microbial synthesis

\section{INTRODUCTION}

Carotenoids are lipophilic tetraterpenoid compounds showing red, orange or yellow pigmentation due to intense absorbance in the visible spectral area. To date isolated natural carotenoids embrace over 700 distinct molecules. Two major types of carotenoids are hydrocarbons $\mathrm{C}_{40} \mathrm{H}_{56}$ (carotenes) and oxygen-containing derivatives (xanthophyles). The lack of $\mathrm{CH}_{3}, \mathrm{CH}_{2}$ and $\mathrm{CH}$ groups in the terminal structure is denoted by prefix "nor", while contraction of carbon skeleton is designated as "apo". Carotenoids represented by geometric isomers are readily transformed (often from $\mathrm{Z}$ to $\mathrm{E}$ ) under the impact of temperature, light and other factors, e.g. organic solvents (Pechinsky and Kuregyan, 2013). Despite the fact that large variety of carotenoids in the environment complicates their functional specification, carotenoids primarily perform the protective role in the cell. Owing to carotenoids microorganisms may colonize luminous habitats, the pigments are engaged in the mechanism governing resistance to ionizing radiation and promote adaptation to extreme conditions, like hydrogen sulphide atmosphere, geotherma springs, concentrated acid and salt solutions (Ventosa et al., 2010; Vsevolodov, 1988). Currently vivid interest to carotenoids is determined by their broad application range as provitamin A and natural colorants in bakery, butter, refreshment drinks, cosmetics; feed premixes in fishery; antioxidants; organic reagents; drugs (Frengova et al., 2004; Jaswir et al., 2011; Mata-Gómez et al., 2014; Saddozai et al., 2005).

Such microorganisms as algae, fungi, bacteria, yeast may serve as sources of carotenoids on a par with plants. Some carotenoids of microbial and alternative origin were licensed for legal use in many countries as food and feed additives. For instance, $\beta$-carotene of carrot, zigomycete fungi Blakeslea trispora and unicellular algae Dunaliella salina is applied as alimentary dye (Nelis and Leenheer, 1990). Production of carotenoids by microbial synthesis is distinguished by the following advantages: presence in the cell of the sole pigment group (not accompanied by chlorophylles), possibility of incubation in the fermenters, fast and controllable growth rates of microbial culture, supply of inexpensive nutrient substrates (Frengova and Beshkova, 2009; Latha et al.,
2005). Carotenoid supplements derived from yeast may be admixed as freezedried biomass, yet hardly digestible rigid cell walls of yeast species (e.g. Phaffia rhodozyma) urge technologists to resort to preliminary cell disintegration (An and Choi, 2003). The promising agents for biotechnological synthesis of carotenoids are red yeast of Rhodotorula genus. Investigations are focused on this microbial group to evaluate economic prospects of pigment production biotechnology. The major types of Rhodotorula yeast carotenoids are $\alpha-, \beta-, \gamma-$ carotenes, torulene, torularhodin, lycopene (Bogdanovskaya et al., 1978), with some substances possessing remarkable practical and commercial value. Noteworthy, that carotene and lycopene have been introduced on a large scale in food industry (bioadditive E160 was approved in European community, Russia, Eastern Europe (Matthäus et al., 2014). Aim of this study was to investigate capacity to synthesize carotenoids on beer wort nutrient medium in 22 strains of red yeast deposited at Belarusian collection of non-pathogenic microorganisms. Brewery wort is alcohol fermentation intermediate of relatively low cost. Research objectives included assessment of biomass and carotenoid production by tested yeast strains and their differentiation in the spectrum of generated pigments, as well as analysis of effect of organic compound supply into the medium on biomass and carotenoid productivity.

\section{MATERIAL AND METHODS}

\section{Yeast strains}

Twenty-two yeast strains of genus Rhodotorula, belonging to the species: $R$. glutinis, R. lactosa, R. minuta, R. aurantiaca, R. mucilaginosa and R. rubra provided from the stock of the Belarusian collection of non-pathogenic microorganisms were used in this study. A list of tested strains is presented in Table 1. The "red" yeast usually colonize the terrestrial, aqueous and air habitats. The collection strains were isolated from samples of soil, high moss peat $(R$. glutinis), water (R. minuta), air (R. mucilaginosa, R. lactosa). 
Table 1 List of yeast strains of genus Rhodotorula deposited at Belarusian collection of non-pathogenic microorganisms

Species and the BIM number

\begin{tabular}{|c|c|c|}
\hline R. glutinis & R. lactosa & R. mucilaginosa \\
\hline BIM Y -10 & BIM Y -118 & BIM Y -161 \\
\hline R. glutinis & R. glutinis & R. mucilaginosa \\
\hline BIM Y-33 & BIM Y -138 & BIM Y -162 \\
\hline R. mucilaginosa & R. aurantiaca & R. glutinis \\
\hline BIM Y-47 & BIM Y -156 & BIM Y -167 \\
\hline R. mucilaginosa & R. glutinis & R. glutinis \\
\hline BIM Y-50 & BIM Y -157 & BIM Y- 243 \\
\hline R. lactosa & R. glutinis & R. glutinis \\
\hline BIM Y -113 & BIM Y -158 & BIM Y- 253 \\
\hline R. minuta & R. glutinis & R. mucilaginosa \\
\hline BIM Y-114 & BIM Y -159 & BIM Y- 254 \\
\hline R. lactose & R. glutinis & R. rubra \\
\hline BIM Y -116 & BIM Y -160 & BIM Y- 268 \\
\hline \multicolumn{3}{|l|}{ R. minuta } \\
\hline BIM Y -117 & & \\
\hline
\end{tabular}

\section{Cultivation of yeast strains of Rhodotorula genus}

The yeast cells were incubated in $500 \mathrm{ml}$ flasks containing $200 \mathrm{ml}$ of beer wort ( 6 $\left.{ }^{\circ} \mathrm{B}\right)$ with constant stirring $(200 \mathrm{rpm})$ at $26^{\circ} \mathrm{C}$ for four days, and in $250 \mathrm{ml}$ flasks containing $100 \mathrm{ml}$ of beer wort $\left(6^{\circ} \mathrm{B}\right)$ with constant stirring $(180 \mathrm{rpm})$ for the experiment with organic additives. The accumulated biomass was freeze-dried.

\section{Recovery of carotenoids and evaluation of their production level}

Yeast cell walls were disrupted in a glass mortar, carotenoids were extracted using acetone and petroleum ether (Rodriguez-Amaya, 2001).

Analysis of the carotenoid synthetic ability was carried out by express method based on measuring absorbance in the visible wavelength area using spectrophotometer "Solar" UV (PB2201). Pigment production level was calculated as $\beta$-carotene via optical absorbance at $450 \mathrm{~nm}$ according to the formula (Sahabi, 2012; Sindhua and Sherief, 2011):

where:

$$
C=\frac{A \times D \times 10^{6}}{100 \times G \times d \times E}
$$

$C$ - Carotenoid concentration, $\mu \mathrm{g} / \mathrm{g}$;

$A$ - Optical density of the solution at $450 \mathrm{~nm}$;

$D$ - Eluate volume, $\mathrm{ml}$;

$E$ - $\beta$-carotene extinction coefficient $(2590$ at $450 \mathrm{~nm})$;

$d$-Cuvette width $(1 \mathrm{~cm})$;

$G$ - Portion of dry biomass collected for carotenoid extraction, $\mathrm{g}$.

\section{Statistics}

The presented data sum up results of three experiments. For statistical interpretation of experimental findings confidence range of arithmetic means at $95 \%$ significance level was computed. Data processing and analysis was performed using software package Microsoft Excel.

\section{RESULTS AND DISCUSSION}

\section{Production of biomass by yeast strains of genus Rhodotorula}

Biomass production is illustrated in Figure 1. After 3 experimental series the highest level of biomass production (more than $10 \mathrm{~g} / \mathrm{l}$ ) was shown by the yeas strains $R$. glutinis BIM Y-10, R. mucilaginosa BIM Y-50, R. lactosa BIM Y-118, R. aurantiaca BIM Y-156, R. glutinis BIM Y-157, R. mucilaginosa BIM Y-162, R. glutinis BIM Y-167, R. rubra BIM Y-268.

\section{Production of carotenoids by yeast strains of genus Rhodotorula}

Since yeast strains of genus Rhodotorula differ in carotenoid extractivity, it is expedient to consider yields of carotenoids recovered by the afore-mentioned method as a consequence of pigment production and subsequent release from cells. In this study the highest yields of carotenoids (over $80 \mu \mathrm{g} / \mathrm{g}$ ) were recorded for the strains $R$. glutinis BIM Y-158 and BIM Y-253, with the peak value achieved in R. glutinis BIM Y-253 culture $(150.9 \pm 78.4 \mu \mathrm{g} / \mathrm{g})$. Carotenoid production data are presented in Figure 1

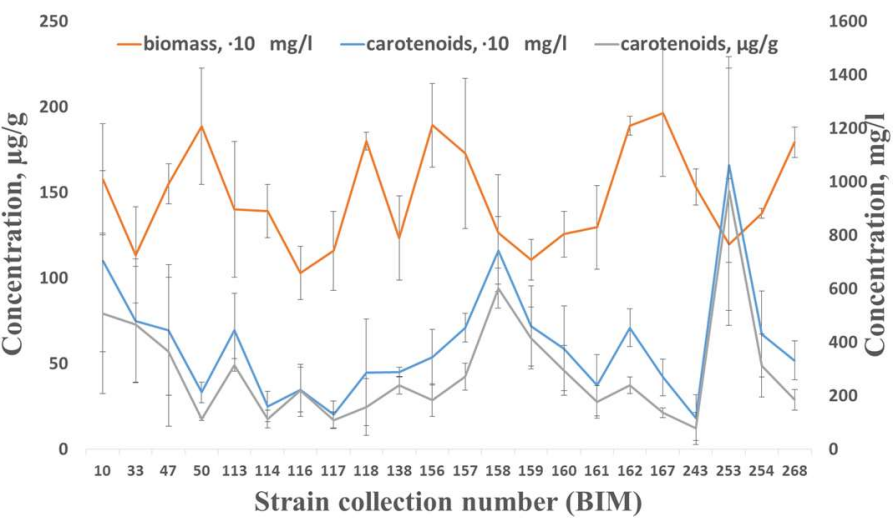

Figure 1 Production of biomass and carotenoids by yeast strains of genus

\section{Rhodotorula}

Yeast strains R. glutinis BIM Y-158 and BIM Y-253 also showed enhanced biomass and carotenoid production capacity: concentration of the pigments exceeded 0.7 and $1 \mathrm{mg} / \mathrm{l}$, respectively.

\section{The absorbance spectra of total carotenoid fractions}

The spectra of yeast pigment fractions demonstrate the presence of typical for carotenoids three peaks of absorbance, with the exception of five strains lacking clear peaks (R. glutinis BIM Y-33 and BIM Y-157, R. lactosa BIM Y-113, BIM Y-116 and BIM Y-118). Carotenoid spectra of the studied microbial group are heterogeneous in distribution of absorbance maxima, indicating the synthesis of diverse prevalent pigments by yeast strains belonging to genus Rhodotorula According to the revealed absorbance maxima, the examined strains can be divided into several groups presented in Table 2. The absorbance spectra of group representatives in the visible region are shown in Figure 2.

Table 2 Grouping of Rhodotorula yeast strains in accordance with absorbance maxima of intracellular pigments

\begin{tabular}{|c|c|c|c|c|c|}
\hline $\begin{array}{l}\text { The } \\
\text { absorbance } \\
\text { peak values }\end{array}$ & $\begin{array}{l}458-465 / \\
485-490 / \\
516-521\end{array}$ & $\begin{array}{l}424-428 / \\
456-466 / \\
487-490\end{array}$ & $\begin{array}{l}437-439 / \\
463-467 / \\
485-489\end{array}$ & $\begin{array}{l}460- \\
465 / \\
487-490\end{array}$ & $\begin{array}{l}459- \\
468 / \\
477- \\
490 \\
\end{array}$ \\
\hline $\begin{array}{l}\text { BIM } \\
\text { collection } \\
\text { strain } \\
\text { number }\end{array}$ & 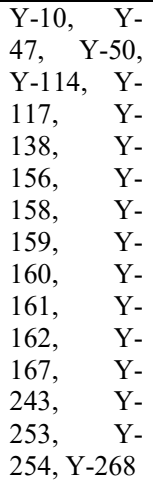 & $\begin{array}{ll}Y-33, & Y- \\
116 & \end{array}$ & Y-113 & Y-157 & Y-118 \\
\hline
\end{tabular}



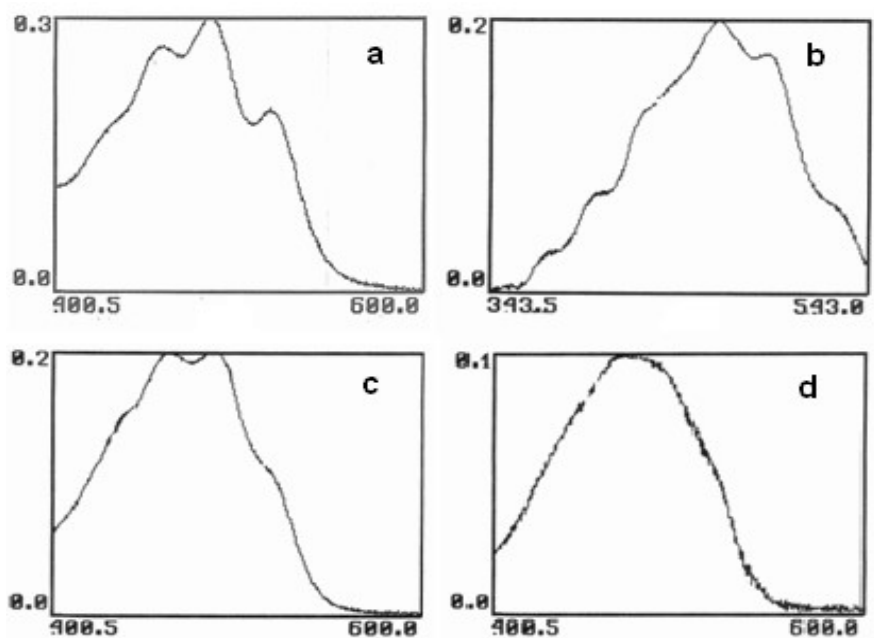

Figure 2 The spectrum of total carotenoids extracted from the cultures: a) $R$ glutinis BIM Y-158 with absorbance maxima at wavelengths 460, 486 and 518 $\mathrm{nm}$; b) R. glutinis BIM Y-33 with absorbance maxima at wavelengths 424,459 and $490 \mathrm{~nm}$; c) $R$. lactosa BIM Y-113 with absorbance maxima at wavelengths 438, 463 and $488 \mathrm{~nm}$; d) $R$. lactosa BIM Y-118 with absorbance maximum at wavelength $468 \mathrm{~nm}$, "shoulder" in the area $477-490 \mathrm{~nm}$.

\section{Effect of organic additives on production of carotenoid-containing biomass by yeast strain R. glutinis BIM Y-253}

Biotechnological production of carotenoids envisages supply of various substances to optimize the process. As a rule, the nutrient medium is supplemented with foam-quenching agents (surfactants), antioxidants (citric acid), vitamins (thiamin) and promoters of biosynthesis ( $\beta$-ionone, 2,6,6trimethyl-1-acetyl hexane) (Tikhonov et al., 2008). Our study examined effect of organic compounds on biomass and carotenoid synthesis by yeast strain $R$. glutinis BIM Y-253 selected as the best producer on beer wort medium. To stimulate carotenogenesis TCA cycle intermediates (citric, fumaric and malic acids in $0.05 \%$ concentrations) or seed oil in concentration $500 \mu 1 / 1$ were fed into the same medium $\left(6^{\circ} \mathrm{B}\right)$. Extraction of carotenoids followed vigorous milling of biomass. The results are presented in Figure 3

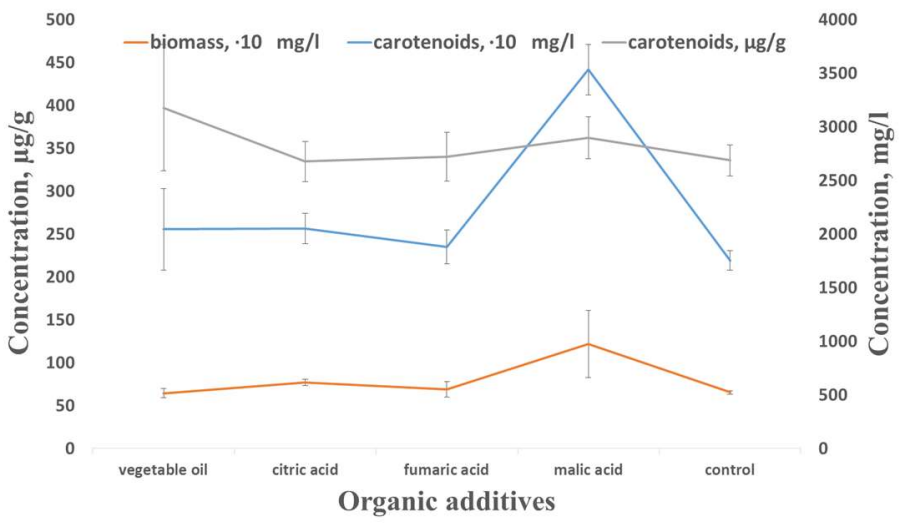

Figure 3 Production of biomass and carotenoids by yeast strain R. glutinis BIM Y-253 on beer wort medium enriched with organic acids and vegetable oil

Carotenoid and biomass biosynthetic capacity of strain BIM Y-253 on beer wort medium supplemented with sunflower seed oil, fumaric, citric and malic acids constituted $2.3 \mathrm{mg} / 1,1.7 \mathrm{mg} / 1,2.1 \mathrm{mg} / 1,3.5 \mathrm{mg} / 1$, respectively. Thus, supply of $0.05 \%$ malic acid into the medium promotes 2.2 times carotenoid yield as compared to the control variants. Enhanced carotenoid ratio in yeast biomass was recorded after addition of sunflower seed oil $(397.22 \pm 73.72 \mu \mathrm{g} / \mathrm{g})$ and malic acid $(362.01 \pm 24.3 \mu \mathrm{g} / \mathrm{g})$

$0.05 \%$ level of malic acid in the medium proved optimal. Dose-dependent effect of malic acid supply into medium on biomass generation of strain BIM Y-253 was observed, with cell-productivity tending to decline at lower $\mathrm{pH}$ values $-\leq 3.0$ (Figure 4).

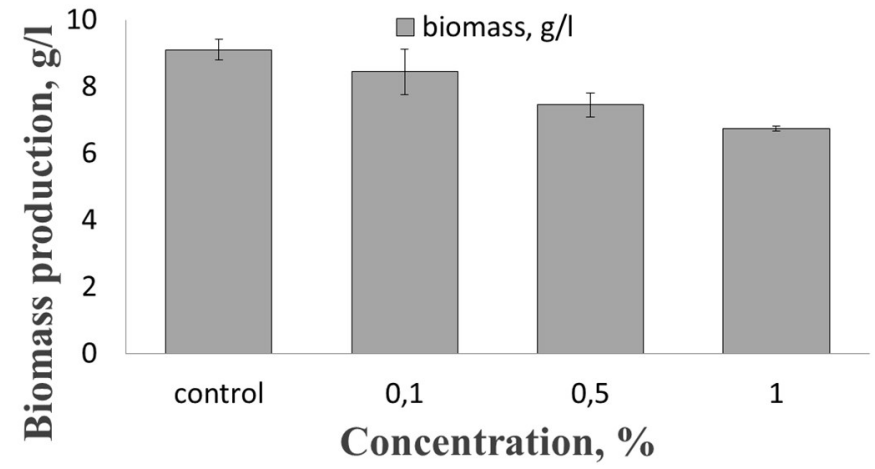

Figure 4 Dose-dependent biomass productivity of yeast strain BIM Y-253 upon supply of malic acid into beer wort nutrient medium

It should be noted that the tested organic compounds did not affect carotenoid spectra.

\section{DISCUSSION}

The highest carotenoid yields were attained by the following strains: $R$. glutinis BIM Y-253 (the ultimate productivity was $150.9 \pm 78.4 \mu \mathrm{g} / \mathrm{g}$ ), and R. glutinis BIM Y-158 $(94.1 \pm 11.7 \mu \mathrm{g} / \mathrm{g})$, respectively. The results of 4 day yeast incubation in beer wort medium $\left(6^{\circ} \mathrm{B}\right)$ correspond to the average carotenoid productivity (at least $100 \mu \mathrm{g} / \mathrm{g}$ ) of Rhodotorula strains. It should be noted that initial values of fermentation parameters, like concentration of the nutrient medium, agitation rate, temperature, incubation time provide for minimal levels of carotenoid productivity. For comparison, the optimum cultivation time for strain Rhodotorula gracilis equalled 9 days in preference to tested 3 and 6 days (Govindaswamy et al., 1999). It was shown for strain $R$. glutinis that the ratio of cell carotenoids plateaued on day 4 of the culture (Tinoi et al., 2005). The maximum growth rate and metabolic activity of $R$. glutinis strains was observed at 29 and $30^{\circ} \mathrm{C}$ (Mata-Gómez et al., 2014). Due to the fact that carotenogenesis is an aerobic process, stirring rates can also be increased. In experiments optimizing conditions of carotenoid synthesis by mutant strain $R$. glutinis the effect of medium composition was evaluated at elevated agitation rate $-250 \mathrm{rpm}$ (Bhosale and Gadre, 2001). Previous studies on synthesis of carotenoids were conducted on natural substrates as carbon sources, such as grape juice, grape must, peat extract and hydrolyzate, sugar cane juice and molasses, milk whey, corn hydrolyzate (Mata-Gómez et al., 2014). For example, when incubated in molasses medium for 3 days at $30^{\circ} \mathrm{C}$ and stirring rate $200 \mathrm{rpm}$, the strain $R$. rubra generated $2.74 \mathrm{mg} / \mathrm{L}$ carotenoids (Banzatto et al., 2013). Production of carotenoids by $R$. glutinis on brewery wastes constituted $0.6 \mathrm{mg} / \mathrm{L}, 1.2 \mathrm{mg} / \mathrm{L}$ and $1.0 \mathrm{mg} / \mathrm{L}$ (crude wastewater, glucose enriched wastewater and synthetic sugar medium, respectively). In the raw and glucose-upgraded wastewater major carotenoids were represented by torularhodin and $\beta$-carotene in approximately equal proportions, whereas torulene, torularhodin and $\beta$-carotene prevailed in a synthetic sugar medium (Schneider et al., 2013). R. glutinis cells displayed different color at temperature $5^{\circ} \mathrm{C}$ and $25^{\circ} \mathrm{C}$ (yellow vs red or pink, respectively). The established distinctions were attributed to high $\beta$-carotene and $\gamma$-carotene levels in cells at $5^{\circ} \mathrm{C}$, whereas rising temperatures increased the ratio of torulene and torularhodin (Bogdanovskaya et al., 1978).

The selective absorbance of waves in the visible range is a vital diagnostic key used for identification of carotenoids by spectrophotometry in the UV and visible wavelength bands. The absorbance maxima of main carotenoids synthesized by Rhodotorula yeast are provided in Table 3. Spectral characteristics of carotenoid fractions from 22 yeast strains (presented in Table 2) evidence the presence of ranges in the values of absorbance maxima of total carotenoids. This observation may be explained by high lability of terpenoid compounds affecting their absorbing properties. Absorbance maxima of torulene and torularhodin correspond to wavelength peak ranges of the first group of yeast (Table 2), the absorbance maximum of $\beta$-carotene - to the second group, $\gamma$-carotene - to the third group. The inference may be deduced from these findings on the predominant synthesis of specific pigments in different carotenogenic yeasts. 
Table 3 Carotenoid absorbance maxima in petroleum ether ${ }^{\mathrm{a}}$

\begin{tabular}{lccc}
\hline Pigment & \multicolumn{3}{c}{ Absorbance maxima in petroleum ether } \\
\hline \multirow{2}{*}{$\alpha$-carotene } & 421 & 445 & 474 \\
& 422 & 444 & 473 \\
\hline \multirow{3}{*}{$\beta$-carotene } & 425 & 453 & 484 \\
& 425 & 451 & 482 \\
& 421 & 451 & 478 \\
$\gamma$-carotene & 425 & 448 & 475 \\
\hline Lycopene & 437 & 461 & 494 \\
\hline Torulene & 437 & 462 & 494 \\
\hline Torularhodin & 446 & 472 & 505 \\
\hline
\end{tabular}

${ }^{\text {a}}$ The data are cited from Kudrytskaya, 1990; Maldonado et al., 2008.

The following experimental series has revealed promoters of growth and carotenoid synthesis for yeast strain Rhodotorula glutinis BIM Y-253. Diverse reports stated stimulating effect of sunflower seed oil and TCA cycle intermediates - citric and malic acids (Kiritsa, 2005). In our study the highest stimulating activity was shown by $0.05 \%$ malic acid. Noteworthy that malate may serve as direct precursor of pyruvate in process mediated by malic enzyme (Garay et al., 2014; Zelle et al., 2010). In turn, pyruvate is located at the junction of major assimilation and dissimilation metabolic pathways (Zhu et al., 2012).

\section{CONCLUSION}

Screening of 22 yeast strains of genus Rhodotorula for carotenoid production capacity allowed to sort out 2 variants with maximal biosynthetic activity referred to species $R$ glutinis. The results shown by these 2 strains match the medium level of carotenoid productivity (above $100 \mu \mathrm{g} / \mathrm{g}$ ) among Rhodotorula yeast under the set conditions and therefore appear attractive for further upgrading of strain characteristics to raise the level of carotenoid production and to optimize pigment generation parameters. Native microbial cultures limited in carotenoid productivity serve as the basis for selection of pigment hyperproducers (Emmerstorfer-Augustin et al., 2016; Guo et al., 2015). For instance, mutagenic treatment of parent strains by nitrosoguanidine, ethy methanesulfonate, UV irradiation resulted in 2.8 -fold rise of synthesized amounts of $\beta$ carotene and other carotenoids by modified $R$. glutinis strains (Cong et al., 2007; Cutzu et al., 2013). In our study the effect of added organic compounds on biomass and carotenoid productivity of yeast strain $R$. glutinis BIM Y-253 was estimated. 4-day strain incubation in beer wort medium supplemented with $0.05 \%$ malic acid at agitation rate $180 \mathrm{rpm}$ in artificial light culture resulted in $3.5 \mathrm{mg} / 1$ carotenoid yield, i.e. 2.2 times up the control values. Under experimental conditions the studied 22 yeas strains displayed prevailing synthesis of torulene and torularhodin. So far the latte pigments are inferior to $\beta$-carotene in volume of industrial output (Braunwald, 2013), yet they possess certain preferential properties, e.g. superior antioxidant activity of torulene due to enhanced number of double bonds in the molecular structure (MataGómez et al., 2014). Elucidation of torularhodin role in acquired tolerance of $R$. mucilaginosa to UV-B-exposure led the researchers to assume significant contribution of other molecular mechanism, apart from antioxidant action, in promoting cell survival during UV-B ray treatment (Moliné et al., 2010). Discovery of new vita functions of modified carotenoid compounds might spur up motivation in biological production of diverse pigments and enlarge the range of microbial cultures involved in manufacturing technologies.

\section{The authors have declared no conflict of interest.}

Acknowledgements: The authors express sincere gratitude to Dr. of Biology M.V. Makarov, Murmansk Marine Biological Institute, KSC RAS, for advisory assistance in the field of pigments of microorganisms.

\section{REFERENCES}

Gil-Hwan, A., \& Choi, E. S. (2003). Preparation of the red yeast, Xanthophyllomyces dendrorhous, as feed additive with increased availability of $\begin{array}{llll}\text { astaxanthin. } \quad \text { Biotechnology 25(10), 767-771 } & \end{array}$ http://dx.doi.org/10.1023/A:1023568319114.

Banzatto, D., Freita, L. A. D., \& Mutton, M. J. R. (2013). Carotenoid production by Rhodotorula rubra cultivated in sugarcane juice, molasses, and syrup. Food Science and Technology (Campinas), 33, 14-18. http://dx.doi.org/10.1590/S0101 20612013000500003.

Bhosale, P., \& Gadre, R. V. (2001). Optimization of carotenoid production from hyper-producing Rhodotorula glutinis mutant 32 by a factorial approach. Letters in applied Microbiology, 33(1), 12-16. http://dx.doi.org/10.1046/j.1472765X.2001.00940.x.

Bogdanovskaya, Zh. N. , Gurinivich, E. S., Obraztsova, N. V., Korolyova, I. F., Andreevskaya, V. D., Mikheeva, L. D. (1978). Products of microbial synthesis on peat substrates. Ed. Zalashko M. V., Minsk: Nauka i Technika Press.

Braunwald, T. (2013). Feasibility of microbial biodiesel and carotenoid production considering the potential of food processing wastewaters as low cost carbon sources using the example of red yeast Rhodotorula glutinis. Dissertation, Institut für Kulturpflanzenwissenschaften, Fakultät Agrarwissenschaften.
Cong, L., Chi, Z., Li, J., \& Wang, X. (2007). Enhanced carotenoid production by a mutant of the marine yeast Rhodotorula sp. hidai. Journal of Ocean University of China (English Edition), 6(1), 66-71. http://dx.doi.org/10.1007/s11802-0070066-x.

Cutzu, R., Coi, A., Rosso, F., Bardi, L., Ciani, M., Budroni, M., ... \& Mannazzu, I. (2013). From crude glycerol to carotenoids by using a Rhodotorula glutinis mutant. World Journal of Microbiology and Biotechnology, 29(6), 1009-1017. http://dx.doi.org/10.1007/s11274-013-1264-x.

Emmerstorfer-Augustin, A., Moser, S., \& Pichler, H. (2016). Screening for improved isoprenoid biosynthesis in microorganisms. Journal of biotechnology, 235, 112-120. http://dx.doi.org/10.1016/j.jbiotec.2016.03.051.

Frengova, G. I., \& Beshkova, D. M. (2009). Carotenoids from Rhodotorula and Phaffia: yeasts of biotechnological importance. Journal of industrial microbiology \& biotechnology, 36(2), 163. http://dx.doi.org/10.1007/s10295 008-0492-9.

Frengova, G. I., Simova, E. D., \& Beshkova, D. M. (2004). Improvement of carotenoid-synthesizing yeast Rhodotorula rubra by chemical mutagenesis Zeitschrift für Naturforschung C, 59(1-2), 99-103. https://doi.org/10.1515/znc2004-1-220.

Govindaswamy, V., Vasudevan, V., \& Divakar, S. (1999). Optimisation of growth parameters for the production of carotenoids by Rhodotorula gracilis Zeitschrift für Lebensmitteluntersuchung und-Forschung A, 208(2), 121-124 https://doi.org/10.1007/s002170050387.

Guo, W., Liu, Y., Yan, X., Liu, M., Tang, H., Liu, Z., \& Zhang, L. (2015) Cloning and characterization of a phytoene dehydrogenase gene from marine yeast Rhodosporidium diobovatum. Antonie van Leeuwenhoek, 107(4), 1017 1027. https://doi.org/10.1007/s10482-015-0394-6.

Noviendri, D., Hasrini, R. F., \& Octavianti, F. (2011). Carotenoids: Sources, medicinal properties and their application in food and nutraceutical industry. Journal of Medicinal Plants Research, 5(33), 7119-7131. https://doi.org/10.5897/JMPRX11.011.

Kudritskaya, S. E. (1990). Carotenoids of fruits and berries. Kiev: Vishcha shkola Press.

Latha, B. V., Jeevaratnam, K., Murali, H. S., \& Manja, K. S. (2005). Influence of growth factors on carotenoid pigmentation of Rhodotorula glutinis DFR-PDY from natural source. Indian Journal of Biotechnology. 4, 353-357.

Maldonade, I. R., Rodriguez-Amaya, D. B., \& Scamparini, A. R. (2008) Carotenoids of yeasts isolated from the Brazilian ecosystem. Food Chemistry, 107(1), 145-150. https://doi.org/10.1016/j.foodchem.2007.07.075.

Mata-Gómez, L. C., Montañez, J. C., Méndez-Zavala, A., \& Aguilar, C. N. (2014). Biotechnological production of carotenoids by yeasts: an overview. Microbial cell factories, 13(1), 12. https://doi.org/10.1186/1475-2859-13-12.

Matthäus, F., Ketelhot, M., Gatter, M., \& Barth, G. (2014). Production of lycopene in the non-carotenoid-producing yeast Yarrowia lipolytica. Applied and $\begin{array}{llll}\text { environmental } & \text { microbiology, } & \text { 80(5), } & 1660-1669\end{array}$ https://doi.org/10.1128/AEM.03167-13.

Moliné, M., Flores, M. R., Libkind, D., del Carmen Diéguez, M., Farías, M. E., \& van Broock, M. (2010). Photoprotection by carotenoid pigments in the yeast Rhodotorula mucilaginosa: the role of torularhodin. Photochemical \& Photobiological Sciences, 9(8), 1145-1151. https://doi.org/10.1039/c0pp00009d. Nelis, H., \& De Leenheer, A. P. (1991). Microbial sources of carotenoid pigments used in foods and feeds. Journal of Applied Microbiology, 70(3), 181 191. https://doi.org/10.1111/j.1365-2672.1991.tb02922.x.

Pechinsky, S., Kuregyan, A. (2013). The structure and biological functions of carotenoids (review). Voprosy biologich., medicin. i pharmacevt. chimii. 9, 4-15 Rodriguez-Amaya, D. B. (2001). A Guide to Carotenoid Analysis in Foods. ILSI Press. P. 42

Saddozai, A., Hameed, T., \& Kousar, S. (2005). Studies on the isolation and purification of carotenoids from fruits and vegetables. Pak. Food Sc, 15(3-4), 43 46.

Sahabi, D. M., Shehu, R. A., Saidu, Y., \& Abdullahi, A. S. (2012). Screening for Total Carotenoids and $\beta$-Carotene in Some Widely Consumed Vegetables in Nigeria. Nigerian Journal of Basic and Applied Sciences, 20(3), 225-227.

Schneider, T., Graeff-Hönninger, S., French, W. T., Hernandez, R., Merkt, N., Claupein, W., ... \& Pham, P. (2013). Lipid and carotenoid production by oleaginous red yeast Rhodotorula glutinis cultivated on brewery effluents. Energy, 61, 34-43. https://doi.org/10.1016/j.energy.2012.12.026.

Sindhu, S., \& Sherief, P. M. (2011). Extraction, characterization, antioxidant and anti-inflammatory properties of carotenoids from the shell waste of arabian red shrimp Aristeus alcocki, ramadan 1938. In Open Conf. Proc. J (Vol. 2, pp. 95103). https://doi.org/10.2174/2210289201102010095.

Tinoi, J., Rakariyatham, N., \& Deming, R. L. (2005). Simplex optimization of carotenoid production by Rhodotorula glutinis using hydrolyzed mung bean waste flour as substrate. Process Biochemistry, 40(7), 2551-2557. https://doi.org/10.1016/j.procbio.2004.11.005.

Ventosa, A., Oren, A., Ma, Y. (2010). Halophiles and hypersaline environments. Current research and future trends. Springer-Verlag, Berlin, Germany.

Vsevolodov, N. N. (1988). Biopigments - photorecorders. Photomaterial on bacteriorhodopsin. Moscow: Nauka Press. 